\title{
Spatial distribution of Hyphaene thebacia and Ziziphus spina Christi in Riverine Forest of Dinder National Park, Sudan
}

\author{
Tahani Ali Hassan \\ Department of Wildlife, College of Natural Resources and Environmental Studies, University of Bahri, Khartoum North, \\ Sudan. Email: tahanihassanm@gmail.com. \\ Copyright (@ 2017 Hassan. This article remains permanently open access under the terms of the Creative Commons Attribution License 4.0, which \\ permits unrestricted use, distribution, and reproduction in any medium, provided the original work is properly cited.
}

Received 11th June, 2017; Accepted 31st June, 2017

\begin{abstract}
Dinder National Park (DNP) consists of many types of trees and also many wildlife species. The purpose of this research was to carry out a vegetation sampling of Hyphaene thebacia and Ziziphus spina Christi by using the Moristas index method to determine their distribution pattern. A total of 60 plots in the park were located to determine the distribution pattern of Ziziphus spina Christi and Hyphaene thebaciais. Ziziphus spina Christi distribution pattern was found to be 1.4 (clumpy) and Hyphaene thebaciais 3.03 (clumpy) and their correlation is -0.3. The presence of those two tree species is mainly as a result of availability of water and on the other hand the result showed that the Hyphaene thebacia and Ziziphus spina Christi are clumpy distributed and the null hypothesis was rejected.
\end{abstract}

Key words: Hyphaene thebacia, Moristas index, vegetation, Ziziphus spina Christi.

\section{INTRODUCTION}

Sudan is an African country located within the tropical region (particularly occupying the Sahara and equatorial zones) owing to Hassan (2003) ecological classification of the vegetation of Sudan. Sudan has a great variety of climate and ecosystem including the sub-Sahara, savannah, wooded savannah, lakes, rivers, hills and coastal regions, each with a distinct group of faunal and floral composition creating diverse ecosystem and as a result a good representation of the African wild species which are consider to be of a great economic, scientific, recreational, biological and cultural values. Most of the vegetation plays a great significant role in maintaining the natural ecosystem and preservation of the wild species fauna and flora (Hassan 2003). Savannah is divided into different types according to various characteristic and certain community and species that they have. Along moisture grade is a wet savannah, this part can be recognized in a various types of species composition, vegetation structure and key ecological processes (Vogt 1995).

Desman (1972), has classified the vegetation of Dinder National Park into four categories- woodland, grassland, open grass land and wooded riverine forest. Hakim et al. (1978) and Abel Hameed (1996) classified it into three types of ecosystems: Acacia seyal - Balanites, Reverie Forest and Mayas (meadows) ecosystems.

Hyphaene thebacia and Ziziphus spina Christi serve as a vital habitat for terrestrial migrator species which spend the dry season in the park and they provide food, cover to wild animals such as baboons, bush bucks and green monkeys and many bird species. Also they protect the environment from the degradation. The objective of this study is to determine the distribution pattern of Hyphaene thebacia and Ziziphus spina Christi and the correlation and association of the two species.

\section{MATERIALS AND METHODS}

\section{The study area}

This study was conducted in Dinder National Park, established in 1935 (Anonymous, 2003). The park which embraces 650,000 ha of land lies between latitude $11^{\circ} 45$ 


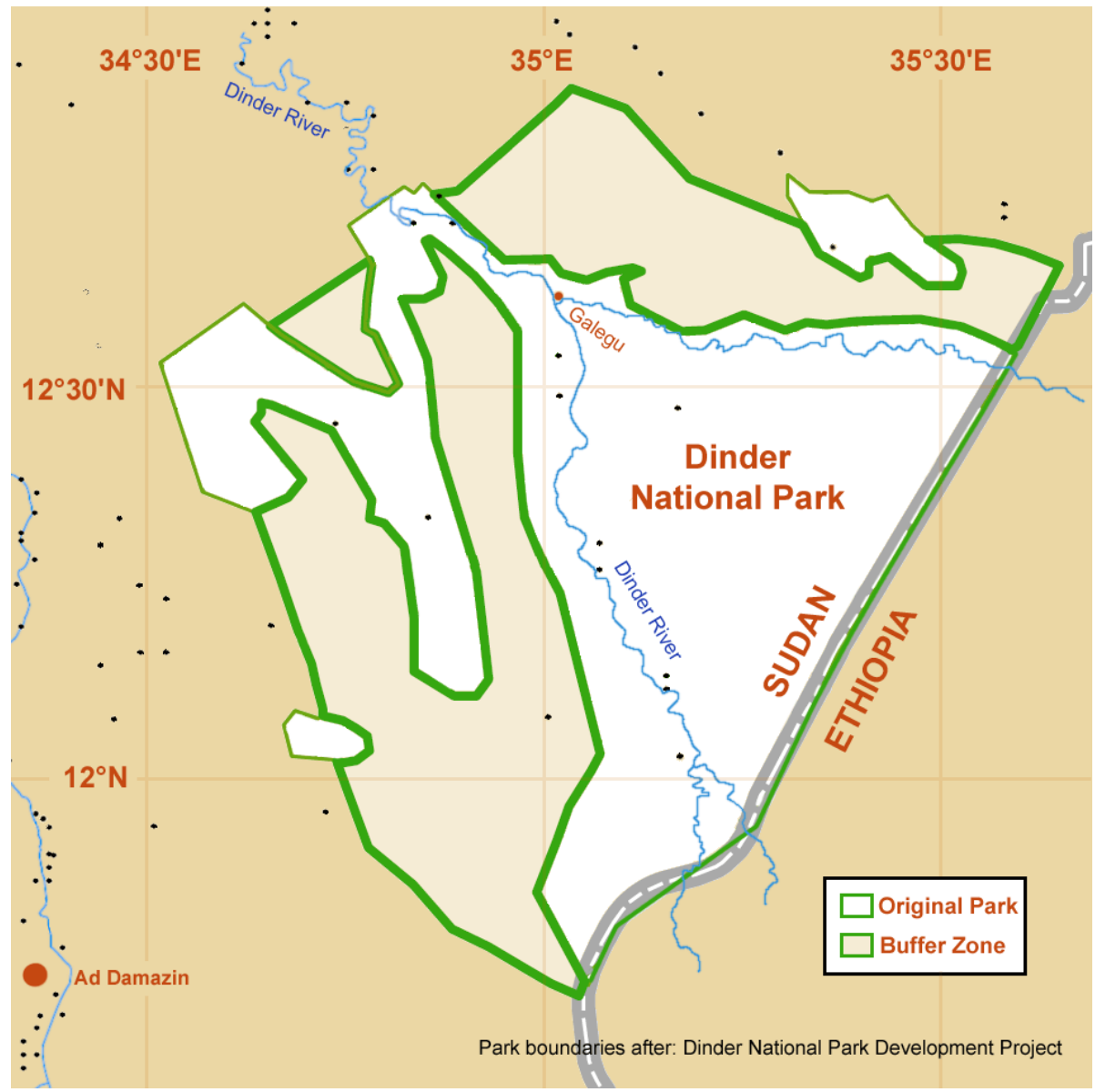

Figure 1.The Dinder National Park (Source: https://www.britannica.com/place/DinderNational-Park retrieved on 4/22/2017).

$\mathrm{E}, 12^{\circ} 50 \mathrm{~N}$ and longitude $34^{\circ} 30 \mathrm{E} 36^{\circ} 00 \mathrm{~N}$ at the south eastern part of Sudan against the Ethiopian frontier (Figure 1). The area of the park principally consists of a low-lying flood plain that slopes gently from the Ethiopian highlands with few rocky hills at its southern corner (Anonymous, 2003). The Rahad and Dinder rivers flow north-westerly through the park area. Tributary streams form seasonally flooded lowlands, known as Mayas (marches) in much of the area adjacent to the Ethiopian border. The park comprises three ecosystems: Maya, Riverine and Dahara (Hakim et al., 1978). Vegetation in the ecosystems consists of grasslands, wooded land and riparian forest.

Along seasonal streams, the vegetation consists of Hyphaene thebaica, Acacia sieberiana, Tamarindus indica and Ficus spp. The under stream vegetation consisting of Ziziphus spina Christi and Mimosa pigra. The herbaceous layer comprises coarse grasses, including Sorghum spp. and Brachiaria spp. Thorn-bush savanna (Acacia seyal-Balanites aegyptica association) with tall grasses dominates the north, while Combretum aculeatum woodland is found in the moister south.
Nymphaea and Ipomoea spp. are common in Mayas with shallow lakes, while the open grass plains are covered by Themeda triandra, Panicum, Hyparrhenia and Cynodon spp. The Mayas, the main source of water and green fodder during the dry season (November to June) are dominated by Echinochloa spp (Hakim et al., 1978).

Dinder National Park has a mean annual rainfall of 600 to $1,000 \mathrm{~mm}$, falling between May and November. When the area of the park was extended by adding $2630 \mathrm{~km}^{2}$, ten villages consequently fell inside the park and there are 38 villages outside its boundary. These villages lie at a distance of less than one kilometer from the boundaries of the park (Anonymous, 2003).

A great variety of species occur within the park and this include Reedbuck (Redunca redunca), Bushbuck (Tragelaphus scriptus), Water buck (Kobus defassa), and warthog (Phacocheorus aethiopicus). The dominant predators include Lion (Panthraleo), and Hyena (Hyena hyena). The primates are represented by olive Baboon (Papio anubis), Green monkey (Cercopithecus aethiops), and patas monkey (Erythrocebu spatas). There is also great variety of birds' species in the park ranging from 
Egyptian goose, Guinea fowl, Ostrich, Pelicans, Marabou stork, Bustards, Heron, Starling, Rollers and Raptors species (Anonymous, 2003).

\section{Materials}

Materials used were 50 and $20 \mathrm{~m}$ steel tape for measuring the distances, data sheet and pen for recording data.

\section{Data collection}

Data collection took place during the daylight hour from 7 am to $5 \mathrm{pm}$, three days a week from January to February in Dinder National Park, during the dry season of 2017. A 50 meter steel tape was used for determining straight transact line. The length of line transact was one $\mathrm{km}$. The data was systematically collected twice from the different directions of khor Galagu riverine forest. 20 plots were taken at the riverine forest in the western part of the park. The second 20 plotss were taken at the southern part of khor Galagu reverine forest and the last 20 plots were taken at the northern part of khor Galagu riverine forest making it a total of 60 plots.

\section{Data analysis}

Moristas (1959) index (ID) of dispersion was used to determine the dispersion and distribution pattern of tree species.

$\mathrm{ID}=\mathrm{n} \times \frac{\sum x 2-N}{\sum x 2-N}$

Where: ID = index of dispersion, $\mathrm{n}=$ number of all plots, $\mathrm{N}=$ number of individual counted in all plots and $\sum x 2=$ summation over all plots the square of the number of individual per plots

If: ID $=1$ it means random

ID $\leq 1$ it means even

ID $\geq 1$ it means clumpy or patchy

Chi- square test was used to test the significance:

$\mathrm{X}^{2}=\frac{\mathrm{k} \sum x 2}{\mathrm{~N}}$

Where: $\mathrm{X}^{2}=$ Chi-square, $\mathrm{k}=$ number of plots, $\sum x 2=$ summation over all plots the square of the number of individual per plots and $\mathrm{N}=$ Total number of individuals counted in plots.

Spearman rank correlation coefficient (SRCC) was used for association of two species:
$\mathrm{R}=1-\frac{6 \sum d 2}{\mathrm{n} 3-\mathrm{n}}$

Where: $d 2=$ different between two ranks of Hyphaene thebacia and Ziziphuss pina Christi and $\mathrm{n}=$ number of pairs of Hyphaene thebacia and Ziziphus spina Christi

If: $R=+1$, it means the ranking have perfect positive association.

$\mathrm{R}=0$, it means the ranking have no correlation or association.

$R=-1$, it means the ranking have perfect negative association.

\section{RESULTS AND DISCUSSION}

In all types of savannah along the Dinder river most of Hyphaene thebacia and Ziziphus spina Christi found mix with other species of Acacia sibriana along the riverine forest.

The index of dispersion for Ziziphus spina Christi is found to be 1.4 while the distribution along the riverine forest of the Dinder Natioal Park is clumpy because the ID is greater than 1 and tested with Chi-square test under the degree of freedom ( $n-1)$ and it is significant because the calculated value of Chi-square test is $83.56^{*}$, is greater than the tabulated value which is greater than $1 \%$ level of significant. In clumped distribution the distance between neighboring individuals is minimize. This type of distribution is found in environments that are characterized by patchy resources. Clumpy distribution is the most common type of dispersion found in nature because animals need certain resources to survive and when these resources become rare during certain time of the year animals tend to clump together around these crucial resources (Table 1).

The distribution of riverine woodland of DNP was found to be 3.03 for Hyphaen ethebacia and clearly indicated that they are clumpy distributed in riverine wood of DNP because the index of dispersion is greater than 1 (ID $\geq 1$ ). Also the Chi-square test is highly significant because the calculated value is greater than $1 \%$ level of significant (Table 2).

The correlation between the of Hyphaen ethebacia and Ziziphus spina Christi correlation coefficient of two species, interpreted total summation of $\mathrm{d}^{2}$ and calculation of SRCC with it clear very low resulted to the value of $r=$ -0.3 and tabulated value of simple linear correlation coefficient at the $5 \%$ and $1 \%$ level of significant. This indicated that the correlation is negative (Table 3 ).

The two species and association number of species summation of $x^{2}$, value of ID, value of chi-square $x^{2}$ is highly significant for each tree but the type of distribution were found for both trees to be clumpy distribution. The correlation of both tree species was negative and null hypothesis of Chi- square of two species are rejected.

These tree species in three directions has no correlation. 
Table 1.Collection and calculation data of Ziziphus spina -christi, in riverine forest of Dinder National Park, during the dry season 2017.

\begin{tabular}{|c|c|c|c|c|c|c|c|c|c|c|c|c|c|c|c|c|c|c|c|c|c|c|c|c|c|c|c|c|c|c|c|c|c|}
\hline Tota No. of individual in one $\operatorname{plot}(\mathrm{x})$ & 3 & 2 & 2 & 1 & 2 & 2 & 3 & 1 & 5 & 1 & 4 & 1 & 3 & 2 & 1 & 2 & 4 & 1 & 2 & 1 & 4 & 3 & 3 & 6 & 1 & 1 & 2 & 4 & 2 & 2 & 1 & 6 & 179 \\
\hline Sum of $x^{2}$ or $\sum x 2$ & 9 & 4 & 4 & 1 & 4 & 4 & 9 & 1 & 25 & 1 & 16 & 1 & 9 & 4 & 1 & 4 & 16 & 1 & 4 & 1 & 16 & 9 & 9 & 36 & 1 & 1 & 4 & 16 & 4 & 4 & 1 & 36 & 1257 \\
\hline
\end{tabular}
$I D=1.4, X^{2}=83.65, P 0.05=46.19, P 0.01=53.5, D F=33$.

Table 2. Collection and calculation data of Hyphaenethebacia, in riverine forest of Dinder National Park, during the dry season 2017.

\begin{tabular}{|c|c|c|c|c|c|c|c|c|c|c|c|c|c|c|c|c|c|c|c|c|c|c|}
\hline Tota No. of individual in one plot( $\mathrm{x}$ ) & 6 & 1 & 4 & 2 & 3 & 1 & 4 & 4 & 10 & 4 & 1 & 4 & 5 & 1 & 4 & 2 & 1 & 1 & 1 & 1 & 1 & 61 \\
\hline Sum of $x^{2}$ or $\sum x 2$ & 36 & 1 & 16 & 4 & 9 & 1 & 16 & 16 & 100 & 16 & 1 & 16 & 25 & 1 & 16 & 4 & 1 & 1 & 1 & 1 & 1 & 283 \\
\hline
\end{tabular}

$I D=3.03, X^{2}=170.9^{* *}, D F=20, P \quad 0.05=31.4, P$ 0.01=37.6.

Table 3.The correlation between HyphaenethebaciaandZiziphusspinaChristi in in riverine forest of Dinder National Park, during the dry season 2017.

\begin{tabular}{|c|c|c|c|c|c|}
\hline Ziziphusspinachristi & R1 & Hyphaenethebacia & $\mathbf{R 2}$ & d & $d^{2}$ \\
\hline 3 & 31 & 0 & 10 & 21 & 441 \\
\hline 2 & 23.5 & 6 & 39 & -15.5 & 240.25 \\
\hline 0 & 4 & 1 & 24 & -20 & 400 \\
\hline 2 & 23.5 & 4 & 34.5 & -11 & 121 \\
\hline 1 & 13 & 2 & 29.5 & -16.5 & 272.25 \\
\hline 2 & 23.5 & 3 & 31 & -7.5 & 56.25 \\
\hline 2 & 23.5 & 1 & 24 & -0.5 & 0.25 \\
\hline 0 & 4 & 4 & 34.5 & -30.5 & 930.25 \\
\hline 0 & 4 & 4 & 34.5 & -30.5 & 930.5 \\
\hline 0 & 4 & 10 & 40 & -36 & 1296 \\
\hline 0 & 4 & 4 & 34.5 & -30.5 & 930.25 \\
\hline 3 & 31 & 1 & 24 & 7 & 49 \\
\hline 1 & 13 & 4 & 34.5 & -21.5 & 462.25 \\
\hline 5 & 38 & 5 & 38 & 0 & 0 \\
\hline 0 & 4 & 1 & 24 & -20 & 400 \\
\hline 1 & 13 & 4 & 34.5 & -25.5 & 462.25 \\
\hline 0 & 4 & 2 & 29.5 & -21.5 & 650.25 \\
\hline 4 & 35.5 & 0 & 10 & 25.5 & 650.25 \\
\hline 3 & 31 & 0 & 10 & 21 & 441 \\
\hline 1 & 13 & 1 & 24 & -11 & 121 \\
\hline 2 & 23.5 & 1 & 24 & -0.5 & 0.25 \\
\hline
\end{tabular}


Table 3. Contd.

\begin{tabular}{|c|c|c|c|c|c|}
\hline 1 & 13 & 1 & 24 & -11 & 121 \\
\hline 2 & 23.5 & 0 & 10 & 13.5 & 182.25 \\
\hline 4 & 35.5 & 0 & 10 & 25.5 & 650.25 \\
\hline 1 & 13 & 0 & 10 & 3 & 9 \\
\hline 2 & 23.5 & 0 & 10 & 13.5 & 182.25 \\
\hline 1 & 13 & 0 & 10 & 3 & 9 \\
\hline 4 & 35.5 & 0 & 10 & 25.5 & 650.25 \\
\hline 3 & 31 & 0 & 10 & 21 & 441 \\
\hline 3 & 31 & 1 & 24 & 7 & 49 \\
\hline 6 & 39.5 & 0 & 10 & 29.5 & 870.25 \\
\hline 1 & 13 & 0 & 10 & 3 & 9 \\
\hline 1 & 13 & 1 & 24 & -11 & 121 \\
\hline 2 & 23.5 & 0 & 10 & 13.5 & 182.25 \\
\hline 4 & 35.5 & 0 & 10 & 25.5 & 650.25 \\
\hline 2 & 23.5 & 0 & 10 & 13.5 & 182.25 \\
\hline 2 & 23.5 & 0 & 10 & 13.5 & 182.25 \\
\hline 1 & 13 & 0 & 10 & 3 & 9 \\
\hline 6 & 39.5 & 0 & 10 & 29.5 & 870.25 \\
\hline 1 & 13 & 0 & 10 & 3 & 9 \\
\hline Sum square & & & & & 13993.2 \\
\hline
\end{tabular}

$R=-0.3^{*}, P 0.05=0.312, P 0.01=0.403$.

Table 4. Results calculated in in riverine forest of Dinder National Park, during the dry season 2017.

\begin{tabular}{|c|c|c|c|c|c|c|c|c|}
\hline Species & No. of trees & Sum of $x^{2}$ & Value of ID & Value of Chi- square $\left(x^{2}\right)$ & Distribution type & P0.05 & P0.01 & SRCC \\
\hline Ziziphusspinachristi & 79 & 257 & 1.4 & $83.65^{\star}$ & Clumpy & 46.2 & 53.5 & -0.3 \\
\hline Hyphaenethebacia & 61 & 283 & 3.03 & $170.9^{* *}$ & Clumpy & 31.4 & 37.5 & Negative \\
\hline
\end{tabular}

Where: ${ }^{*}=$ significant, ${ }^{* *}=$ highly significant, $\mathrm{P} 0.05=$ probability at $5 \%$ level of significant, $\mathrm{P} 0.01=$ probability at $1 \%$ level of significant, $\mathrm{SRCC}=\mathrm{spearman}$ rank correlation coefficient.

They occur due to climatic factors such as soil or habitat requirement of the species (Table 4).

\section{Conclusion}

The total number of tree species was found to be
79 and 61 and sum of $x$ is 257,283 , value of ID is 1.4 and 3.3 , value of $x^{2}$ is $83.65^{*}, 170^{* *}$ respectively for Ziziphus spinachristi and Hyphaene thebacia. The type of dispersion is clumpy for the two species and correlation is negative SRCC (-0.3).

\section{Recommendations}

1. Control the spread of Acacia seyal could be by cutting and selling them at local markets and nearby villages to avoid the entrance of people to the park for that purpose. 
2. Establishment of fire lines to control the annual fires incident.

\section{CONFLICT OF INTEREST}

The author declares that there is no conflict of interest.

\section{REFERENCES}

Hameed, A. (1996). Biosphere Reserves in Sudan. Between Theory and Implementation. The Fourth Scientific Conferences, National Centre for Research, April, 6-8, 1996.

Anonymous (2003). Dinder National Park Management Plan study. Higher Council for Environment and Natural Resources, Wildlife Conservation General Administration. Pp. 51-54.

Desman, W. P. (1972). Development and Management of the Dindir National Park and it is Wildlife. Report of the Government of the Sudan.FAO, Rome. p. 61.
Hakim, S., Fadlalla, B., Awad, N. M., Abdelwahab, S. A. (1979). Ecosystems of the vegetation of Dinder National Park. Unpublished report. Wildlife Research Centre, Khartoum.

Hassan, T. A. (2003). Population sizes and habitat use by four key ungulate species (waterbuck, reedbuck, Oribi and roan antelope) in DNP. B. Sc. Thesis, Department of wildlife sciences, University of Juba, Sudan.

Moristas. M. (1959) measuring of dispersion of individual and analysis of distributional pattern. Mm FacSci, Kyushu Univ. SerE Bio., 2, 215-235

Vogt. k (1995). A field Guide to the identification, propagation and uses of the of common trees and shrubs of dry land Sudan. SOS Sahel international (UK). Pp. 95-98. 